\title{
Seasonal and temporal trends in all-cause and malaria mortality in rural Burkina Faso, 1998-2007
}

\author{
Eveline Otte im Kampe ${ }^{1,4}$, Olaf Müller ${ }^{1 *}$, Ali Sie ${ }^{2}$ and Heiko Becher ${ }^{1,3}$
}

\begin{abstract}
Background: High mortality levels in sub-Saharan Africa are still a major public health problem. Children are the most affected group with malaria as one of the major causes of death in this region. To plan health interventions, reliable empirical information on cause-specific mortality patterns is essential, yet such data are often not available in developing countries. Health and Demographic Surveillance Systems (HDSS) implementing the verbal autopsy (VA) method provide such data on a longitudinal basis. Physician Coded VA is usually used to determine cause of death, but recently a computerized method, Interpreting VA (InterVA) was alternatively introduced. This study investigates the effect of season on all-cause and malaria mortality analysing cause of death data from 1998 to 2007 obtained by the Nouna HDSS in rural Burkina Faso and derived by InterVA.
\end{abstract}

Methods: Monthly mortality rates were calculated for different age groups (infants, children, adolescents, adults, elderly). Seasonal and temporal trends were modelled with parametric Poisson regression adjusted for sex, area of residence and year of death.

Results: Overall, 7,378 deaths occurred corresponding to a mortality rate of 11.9/1,000 with highest rates in infants $(56.8 / 1,000)$ and children $(22.0 / 1,000)$. Young children were most affected by malaria. Malaria mortality patterns in children showed significantly higher rates during the rainy season and a stagnant long-term trend. The seasonal trend is well described parametrically with a sinusoidal function. InterVA assigned about half as many deaths to malaria than physicians.

Conclusions: Malaria mortality remains highly seasonal in rural Burkina Faso. The InterVA method appears to determine reasonably well seasonal mortality patterns, which should be considered for the planning of health resources and activities.

Keywords: Malaria, Mortality, Season, Burkina Faso, Cause of death assignment, Sub-Saharan Africa, Time-seriesanalysis, Fourier-terms

\section{Background}

High mortality levels in sub-Saharan Africa (SSA) are still a major public health problem. This region has the highest rates of childhood mortality with one in eight children facing a probability of dying before age five-that is more than 17 times the average in developed regions [1]. A review of reports from Health and Demographic

\footnotetext{
*Correspondence: olaf.mueller@urz.uni-heidelberg.de

${ }^{1}$ Institute of Public Health, University of Heidelberg, Heidelberg, Germany Full list of author information is available at the end of the article
}

Surveillance (HDSS) sites in SSA presented pneumonia, diarrhoea and malaria as the main causes of childhood mortality [2], which are preventable and also possible to treat [1]. Another study analysing data from a malaria holoendemic area of north-western Burkina Faso for the time period 1999-2003 showed that malaria was with about $40 \%$ the most common cause of death with highest mortality rates among infants aged 6-11 months [3]. Increases in funding and special efforts to fight and prevent malaria in SSA during the last decades have shown critical progress and a widespread reduction of malaria

\section{Biomed Central}

(c) 2015 Otte im Kampe et al. This article is distributed under the terms of the Creative Commons Attribution 4.0 International License (http://creativecommons.org/licenses/by/4.0/), which permits unrestricted use, distribution, and reproduction in any medium, provided you give appropriate credit to the original author(s) and the source, provide a link to the Creative Commons license, and indicate if changes were made. The Creative Commons Public Domain Dedication waiver (http://creativecommons. org/publicdomain/zero/1.0/) applies to the data made available in this article, unless otherwise stated. 
morbidity and mortality [4]. However, about $90 \%$ of all malaria deaths worldwide still occur in SSA with children under the age of five as the most affected group [5].

Cause-specific mortality data and information on mortality patterns is very valuable for policy makers to set health priorities for their population and to plan and establish appropriate and proven interventions [6]. Yet, reliable information on the characteristics and health of certain populations is deficient in the developing world [7]. To provide empirical population and health data in developing countries, HDSSs have been established [8] using the verbal autopsy (VA) method to collect causespecific mortality information in resource-constrained settings [7]. After someone has died, trained field staff conducts an interview with one of the closest relatives of the deceased about signs, symptoms, and circumstances preceding death. However, there might be bias in remembering, reporting and recording such information and the comparability of VA data between different countries is limited by diverse questionnaire designs, different approaches of the interviewers and in interpreting the gathered information although efforts towards standardization have been made [9-11]. The VA method has high rates of sensitivity and specificity for diseases that manifest with a well-defined and unique set of symptoms such as neonatal tetanus, measles, and accidents, but this instrument is less able to discriminate between diseases with overlapping symptoms such as malaria and pneumonia or HIV/AIDS and tuberculosis [12, 13]. It has been shown that VA can overestimate malaria deaths in both low and high transmission settings even where the proportional mortality of malaria among a particular population is very low [14-16].

However, despite obvious limitations the VA method is at present the principle way to study cause of death (COD) information in the developing world and has consequently been applied in a number of countries [17].

Later, VA data can be interpreted to identify a COD [18] by different methods, such as physician review and interpretation of verbal autopsy (InterVA) [19]. Physician-certified verbal autopsy (PCVA) is still the most common approach to interpret VA data [20] in which local physicians review the questionnaires and assign a probable COD [16, 21-24]. Arguments against physician-based certification of CODs from VAs are variations in interpreting VA data due to different training, experience, and/or perceptions of local epidemiology of the reviewing physicians and difficulties of maintaining quality work over long periods of time [25].

A new method to interpret VA data is a computerized model known as InterVA (Interpreting Verbal Autopsy). Although InterVA relies on symptom reports for its algorithmic approach to assigning cause of death it is a more consistent approach than PCVA [26]. Based on Bayes' probability theorem the InterVA model weights symptoms reported during the VA process in relation to specific CODs and determines up to three probable CODs and their corresponding likelihoods [27].

Despite the considerable number of studies analysing mortality patterns in SSA [2-4, 17, 28, 29], relatively few have set their focus on seasonal patterns [3, 30-36]. An analysis of HDSS data on CODs determined by PCVA from a malaria holoendemic region in Burkina Faso investigated seasonal patterns of malaria mortality for the period 1999-2003 [33] and found consistently higher childhood mortality during and at the end of the wet season, when transmission intensity of malaria is at its highest. Since that study used COD data interpreted by physicians only who are known to overdiagnose malaria in holoendemic regions [37, 38], the aim of this study is to investigate the impact of season on all-cause and malaria mortality in different age groups using InterVA COD data. In addition, a larger observation period including more recent data was analysed for the present study taking into account the effect of year on mortality, which was not done in the previous analysis.

\section{Methods}

\section{Study population}

This study is based on data from the Nouna HDSS which had 80,000 individuals at the end of 2007. It is run by the Centre de Recherche en Santé de Nouna [39] and located in the North-West of Burkina Faso in a rural area predominated by a sub-Sahelian climate with one rainy (June-October) and dry (November-May) season per year $[3,40]$. This study covers the observation period from 1 January 1998 to 31 December 2007. Data for Nouna town could only be analysed since 1 January 2000 after Nouna town was integrated into the study area.

To record COD data, the Nouna HDSS has been applying the VA method since 1993. After a death has occurred, trained interviewers visit the household of deceased people in the study area to conduct the VA interview using a standardized questionnaire after obtaining oral informed consent. Most VA interviews are carried out between 3 and 6 months after death allowing for the mourning period [41].

For this study, the InterVA-3 method was applied here to derive the most likely cause of 35 possible COD groups [42]. A detailed description of the InterVA model has been given elsewhere [43]. In short, the InterVA model defines the probability of a cause for a particular death given the presence of a specific disease indicator or symptom using an automated Bayesian model [26]. It displays up to three probable CODs and their corresponding likelihoods. In order to consider local epidemiology 
for important diseases in the Nouna HDSS region, the malaria and HIV/AIDS prevalence was set to "high" for malaria and to "low" for HIV/AIDS [44]. Results will be compared with the previously most often used method to derive the cause of death from VA data, i.e. physician coding.

\section{Data analysis}

All individuals registered in the Nouna HDSS within the study period were included in the analysis except a few individuals $(\mathrm{N}=97)$ for whom no information on month of death were available. To calculate monthly mortality rates, the population by month, year, sex, age group, and area (Nouna town and rural) was estimated as the average of the population at the beginning and end of a month (mid-month-population). Age groups were defined as follows: infants ( $<1$ year), children ( 1 to $<5$ years), adolescents ( 5 to $<15$ years), adults ( 15 to $<60$ years) and the elderly (60+ years). Likewise, the total number of deaths in these categories was calculated. For malaria-specific analysis, the groups "malaria", "other causes", and a third category containing missing causes either due to missing data or causes that could not be determined by either method (PCVA or InterVA) were considered. Only CODs with the highest likelihood as estimated by InterVA, were considered as COD for an individual in the analysis.

The monthly mortality rates $\mu$ per 1,000 were calculated as $\mu=(D / M) \times 1,000$ in which $D$ denotes the number of deaths in the respective month. $M$ denotes the approximate estimate of the person-years, estimated by dividing the mid-month-population by 12 .

To analyse malaria mortality, an imputation procedure was used to consider deaths with missing verbal autopsy questionnaire. The probability that a death with missing questionnaire was due to malaria was estimated by a loglinear model depending on age group and month. The number of deaths with missing VA questionnaire, multiplied with this probability is then the expected number of additional malaria deaths in a given month and age group.

For graphical assessment of seasonal variations and long-term trends, a weighted 5-month moving average (MA) was used according to

$$
\begin{aligned}
\mathrm{MA}_{\text {month }}= & 0.4 \times \mu_{\text {month }}+0.2 \times\left(\mu_{\text {month }+1}+\mu_{\text {month }-1}\right) \\
& +0.1 \times\left(\mu_{\text {month }+2}+\mu_{\text {month }-2}\right) .
\end{aligned}
$$

For assessing the relative monthly effect on overall and malaria mortality, age group-specific Poisson regression models were fitted according to

Model I

$$
\left.\ln \left[\mu\left(\mathrm{x}_{1}, \mathrm{x}_{2}, \mathrm{x}_{3}, \mathrm{x}_{4}\right)\right]=\beta_{1} \mathrm{x}_{1}+\beta_{2} \mathrm{x}_{2}+\beta_{3} \mathrm{x}_{3}+\beta_{4} \mathrm{x}_{4}\right)
$$

and

Model II

$$
\ln \left[\mu\left(\mathrm{x}_{2}, \mathrm{x}_{3}, \mathrm{x}_{4}\right)\right]=\beta_{0}+\beta_{2} \mathrm{x}_{2}+\beta_{3} \mathrm{x}_{3}+\beta_{4} \mathrm{x}_{4}
$$

Model $\mathrm{I}$ is defined as a model without intercept, where $\mathrm{x}_{1}$ is a vector with binary dummy variables for each month, $\mathrm{x}_{2}$ is a continuous variable for calendar year running from 1 (year 1998) to 10 (year 2007) to investigate an overall change in rates over time, $x_{3}$ represents sex and $x_{4}$ area. Model I has no intercept and calculates an estimate for each month. In Model II, an intercept $\beta_{0}$ instead of a monthly effect is estimated. The relative monthly effect on mortality was calculated by the difference $\beta_{1}-\beta_{0}$ of the monthly effect of Model I and the overall effect of model II.

To further assess the seasonal effect on malaria mortality, rate rations (RRs) were estimated using a Poisson regression model with a continuous function of month of death. For this, a sine-function was used of the form $\mathrm{g}_{1}\left(\mathrm{x}_{1}\right)=\sin \left(\mathrm{x}_{1} \times \pi / 6\right)$ and a cosine-function of the form $g_{2}\left(x_{1}\right)=\cos \left(x_{1} \times \pi / 6\right)$ in which $x_{1}$ adopts a value between 1 and 12, corresponding to the months January to December. This resulted in the model

Model III

$$
\begin{gathered}
\ln \left[\mu\left(\mathrm{x}_{1}, \mathrm{x}_{2}, \mathrm{x}_{3}, \mathrm{x}_{4}\right)\right]=\beta_{0}+\beta_{11} g_{1}\left(\mathrm{x}_{1}\right) \\
+\beta_{12} g_{2}\left(\mathrm{x}_{1}\right)+\beta_{2} \mathrm{x}_{2}+\beta_{3} \mathrm{x}_{3}+\beta_{4} \mathrm{x}_{4} .
\end{gathered}
$$

From the regression parameters $\beta_{11}$ and $\beta_{12}$ the amplitude is calculated as $\sqrt{\beta_{11}^{2}+\beta_{12}^{2}}$ and the phase $\varphi$ as $\arctan \left(-\beta_{11} / \beta_{12}\right)$ which determines the day of the year with the highest rate. To test the strength of evidence, the difference of deviances of Model II and III was calculated which is asymptotically $\chi 2$-distributed with two degrees of freedom since two parameters $\left(\beta_{11}, \beta_{12}\right)$ are estimated. Effects are calculated as logarithmic RR.

Since Nouna town was encompassed in the study area in 2000, 432 out of 480 observations, determined by all possible cross-classifications of the variables year, sex and area for which people were observed, were included in each model. For every model 48 observations were set missing, because the number of individuals in these observations was zero. Data analysis was carried out with SAS, 9.2. Poisson regression used the SAS-procedure PROC GENMOD.

\section{Results}

During the whole study period, 7,378 deaths occurred, corresponding to a crude mortality rate of $11.9 / 1,000$ (95\% CI 11.7-12.2). From these, a total of 5,621 (76.2\%) VA questionnaires were completed. Table 1 shows the numbers of missing VAs with highest proportions for infants and young people. The average proportion of 
Table 1 Deaths, missing verbal autopsy (VA) questionnaires and missing causes due to no consensus between physicians, undetermined and ill-defined causes by age group, Nouna HDSS, 1998-2007

\begin{tabular}{|c|c|c|c|c|c|c|}
\hline & Infants $(<1)$ & Children (1-4) & Adolescents (5-14) & Adults (15-59) & Elderly $(60+)$ & Total \\
\hline Deaths & 1,436 & 1,927 & 452 & 1,580 & 1,983 & 7,378 \\
\hline Missing VAs & 384 & 443 & 116 & 388 & 426 & 1,757 \\
\hline Missing VAs (\%) & 26.7 & 23.0 & 26.7 & 24.6 & 12.4 & 23.8 \\
\hline No consensus & 64 & 98 & 25 & 125 & 174 & 486 \\
\hline No consensus (\%) & 4.5 & 5.1 & 5.5 & 7.9 & 8.8 & 6.6 \\
\hline III-defined & 55 & 65 & 45 & 183 & 295 & 643 \\
\hline III-defined (\%) & 3.8 & 3.4 & 10.0 & 11.6 & 14.9 & 8.7 \\
\hline Undetermined & 86 & 112 & 35 & 105 & 160 & 498 \\
\hline Undetermined (\%) & 6.0 & 5.8 & 7.7 & 6.6 & 8.1 & 6.7 \\
\hline
\end{tabular}

missing VAs was $23.8 \%$ and continuously decreased over the time of the observation period.

Usually, if two physicians cannot agree on a COD, a third physician reviews the VA questionnaire to determine a COD. However, if a third physician was not available due to constraint resources or all three physicians determined a different COD, this might result in additional missing CODs. Numbers for these PCVA missings were very similar for the first three age groups but increased for adults and old people. Numbers of ill-defined PCVA CODs resulting from insufficient or unclear information were relatively small for children under age five but increased for the older age groups. The "undetermined" category among the InterVA CODs encompasses all deaths, which could not be determined by the InterVA model. It is larger for infants and children $(\sim 6 \%)$ than in the ill-defined category determined by PCVA. For the older age groups, an opposite picture is shown. Here, the percentage of undetermined causes is smaller than in the ill-defined category.

The all-cause mortality rate over the whole study period was 56.8/1,000 (95\% CI 53.9-59.8) for infants, 22.0/1,000 (95\% CI 21.0-23.0) for children, 2.5/1,000 (95\% CI 2.3-2.7) for adolescents, 5.4/1,000 (95\% CI $5.2-5.7)$ for adults and 56.3/1,000 (95\% CI 53.8-58.8) for the elderly (see Table 2). According to the InterVA coding method, high malaria mortality rates were found only for infants $(8.0 / 1,000 ; 95 \%$ CI 6.9-9.1). This is in contrast to malaria mortality estimates of CODs determined by PCVA showing relatively high malaria mortality also among children and the elderly with rates of 9.4/1,000 (95\% CI 8.7-10.0) and 8.1/1,000 (95\% CI 7.2-9.1), respectively. Overall, significantly less malaria causes were determined by InterVA than by PCVA except for adults. Here, the malaria mortality rate was with $0.4 / 1,000$ (95\% CI 0.3-0.4) for PCVA significantly lower in comparison to InterVA with $0.6 / 1,000$ (95\% CI $0.5-0.7)$. For adults, both methods showed that the proportion of malaria was the smallest and deaths assigned to the "other causes" category accounted for more than half of all adult deaths. A full analysis of COD is not intended here.

Figure 1 presents the age-specific relative monthly effect on all-cause mortality. For infants and children, the logarithmic RRs were higher in the months of the wet season, whereas old people showed an opposite trend. The relative monthly effect for youth and adults is similar to the trend for the oldest, but the picture is less clear. For all age groups, the variation of the monthly rates was significant.

In Fig. 2 the modelled monthly mortality rates and the MA of the rates are illustrated for malaria diagnoses based on InterVA over the whole study period. Infants and children were combined in this analysis. A remarkable agreement was observed between the model-based estimates (in red) and the moving average estimates (in blue). A slight decreasing trend of malaria mortality was observed over the whole study period which is however highly significant $(\mathrm{p}=0.0001)$.

\section{Discussion}

This study adds further evidence to a continuously huge impact of malaria on mortality in young children of rural malaria endemic regions of SSA [3, 17, 45-50]. While a large proportion of deaths in infants were attributed to malaria (20.7/1,000; 95\% CI 19.0-22.5) by physicians' diagnosis, InterVA attributed much less of all infant deaths to malaria. A similar pattern occurred for diagnoses in adolescents, adults and the elderly, but with a much lower proportion of deaths attributed to malaria. In the elderly, physicians attributed a much higher proportion of deaths to malaria compared to InterVA [17], which is likely based on the assumption of a weakening immune system among the elderly $[40,51,52]$. Overall, physicians assigned more deaths to malaria than InterVA did, clearly 
Table 2 Mortality by age and coding method, Nouna HDSS, 1998-2007 (rates per 1,000)

\begin{tabular}{|c|c|c|c|c|c|c|}
\hline & Infants $(<1)$ & Children (1-4) & Adolescents (5-14) & Adults (15-59) & Elderly (60+) & Total \\
\hline \multicolumn{7}{|l|}{ PCVA } \\
\hline \multicolumn{7}{|l|}{ Malaria } \\
\hline $\mathrm{N}$ & 524 & 823 & 105 & 108 & 286 & 1,846 \\
\hline Rate & 20.7 & 9.4 & 0.6 & 0.4 & 8.1 & 3.0 \\
\hline $95 \% \mathrm{Cl}$ & $19.0-22.5$ & $8.7-10.0$ & $0.5-0.7$ & $0.3-0.4$ & $7.2-9.1$ & $2.8-3.1$ \\
\hline$\%$ & 36.5 & 42.7 & 23.2 & 6.8 & 14.4 & 25.0 \\
\hline \multicolumn{7}{|c|}{ Other causes } \\
\hline $\mathrm{N}$ & 458 & 563 & 178 & 831 & 875 & 2,905 \\
\hline Rate & 18.1 & 6.4 & 1.0 & 2.9 & 24.8 & 4.7 \\
\hline $95 \% \mathrm{Cl}$ & $16.5-19.8$ & $5.9-7.0$ & $0.8-1.1$ & $2.7-3.1$ & $23.2-26.5$ & $4.5-4.9$ \\
\hline$\%$ & 31.9 & 29.2 & 39.4 & 52.6 & 44.1 & 39.4 \\
\hline \multicolumn{7}{|c|}{ III-defined + missing } \\
\hline N & 454 & 541 & 169 & 641 & 822 & 2,627 \\
\hline Rate & 18.0 & 6.2 & 0.9 & 2.2 & 23.3 & 4.2 \\
\hline $95 \% \mathrm{Cl}$ & $16.3-19.6$ & $5.7-6.7$ & $0.8-1.1$ & $2.0-2.4$ & $21.7-24.9$ & $4.1-4.4$ \\
\hline$\%$ & 31.6 & 28.1 & 37.4 & 40.6 & 41.5 & 35.6 \\
\hline \multicolumn{7}{|l|}{ Total } \\
\hline $\mathrm{N}$ & 1,436 & 1,927 & 452 & 1,580 & 1,983 & 7,378 \\
\hline Rate & 56.8 & 22.0 & 2.5 & 5.4 & 56.3 & 11.9 \\
\hline $95 \% \mathrm{Cl}$ & $53.9-59.8$ & $21.0-23.0$ & $2.3-2.7$ & $5.2-5.7$ & $53.8-58.8$ & $11.7-12.2$ \\
\hline \multicolumn{7}{|l|}{ InterVA } \\
\hline \multicolumn{7}{|l|}{ Malaria } \\
\hline N & 203 & 342 & 49 & 178 & 53 & 825 \\
\hline Rate & 8.0 & 3.9 & 0.3 & 0.6 & 1.5 & 1.3 \\
\hline $95 \% \mathrm{Cl}$ & $6.9-9.1$ & $3.5-4.3$ & $0.2-0.3$ & $0.5-0.7$ & $1.1-1.9$ & $1.2-1.4$ \\
\hline$\%$ & 14.1 & 17.7 & 10.9 & 11.3 & 2.7 & 11.2 \\
\hline \multicolumn{7}{|c|}{ Other causes } \\
\hline N & 806 & 1,103 & 268 & 959 & 1,421 & 4,557 \\
\hline Rate & 31.9 & 12.6 & 1.5 & 3.3 & 40.3 & 7.4 \\
\hline $95 \% \mathrm{Cl}$ & $29.7-34.1$ & $11.8-13.3$ & $1.3-1.7$ & $3.1-3.5$ & $38.2-42.4$ & $7.2-7.6$ \\
\hline$\%$ & 56.1 & 57.2 & 59.3 & 60.7 & 71.7 & 61.8 \\
\hline \multicolumn{7}{|c|}{ Undetermined + missing } \\
\hline $\mathrm{N}$ & 421 & 490 & 134 & 438 & 513 & 1,996 \\
\hline Rate & 16.7 & 5.6 & 0.7 & 1.5 & 14.5 & 3.2 \\
\hline $95 \% \mathrm{Cl}$ & $15.1-18.3$ & $5.1-6.1$ & $0.6-0.9$ & $1.4-1.7$ & $13.3-15.8$ & $3.1-3.4$ \\
\hline$\%$ & 29.3 & 25.4 & 29.6 & 27.7 & 25.9 & 27.1 \\
\hline
\end{tabular}

due to physicians' tendency to overdiagnose malaria in malaria-endemic areas [37, 38]. An exception could be seen in female adults. Most non-pregnant women in SSA have been exposed to falciparum malaria and are semiimmune to this disease [53]. Local physicians might expect pregnant women living in malaria holoendemic regions to be semi-immune and tend to diagnose other infections than malaria. Given that most adult women in this study were of reproductive age (15-49) this might explain the higher malaria mortality levels according to InterVA diagnoses in comparison to PCVA. However, it cannot fully be judged which method is closer to the real values.

One limitation of this study is the high proportion of unknown CODs due to missing VA questionnaires or insufficient data resulting in assignment of deaths to the "ill-defined"/"undetermined" category. It is very likely that among deaths with unknown cause some were due to malaria. The imputation method used in the analysis was based on the reasonable assumption that deaths with unavailable verbal autopsy information were equally likely to have died of malaria as cases with VA 


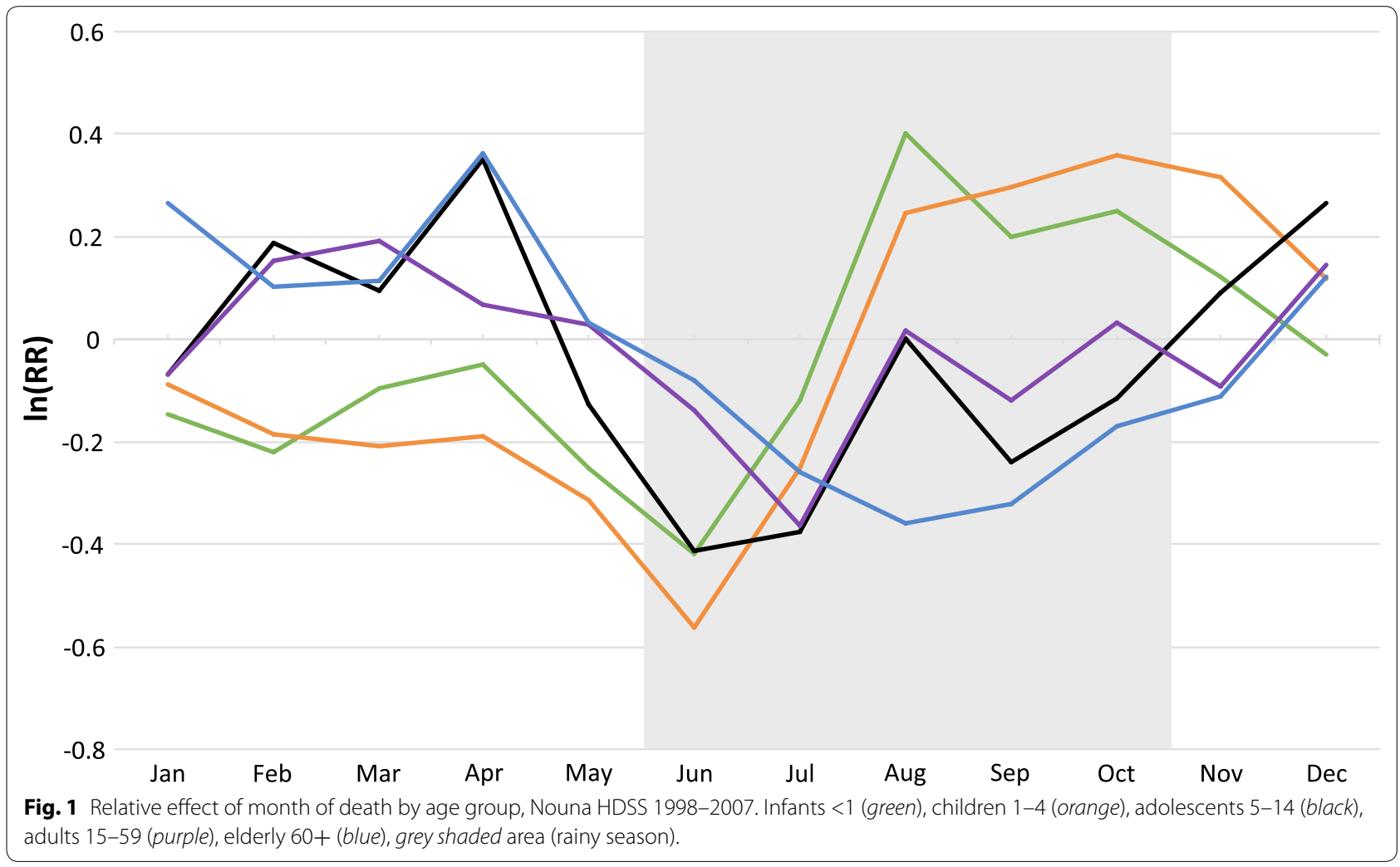

information. If all these deaths were considered as causes other than malaria, the results would have been similar, however the amplitude in Fig. 2 would be about twenty percent lower.

Moreover, there are well-known limitations of the VA method itself relating to the validity of CODs, especially for diseases with non-specific symptoms like malaria. Overlapping symptoms between malaria and diseases such as acute respiratory infection may lead to misclassification of diagnoses and affect the accuracy of the results. Such inaccuracies might additionally be due to variations in VA sensitivity for malaria deaths, depending in areas of high transmission intensity more on the incidence and prevalence of malaria than on exact diagnostic definition [47]. The decrease in VA specificity for malaria with increasing malaria proportional mortality [47] is accompanied by lower sensitivity of VA for other CODs in sites with intense malaria transmission [54]. Thus, use of VA data makes it difficult to estimate the entire impact of malaria on mortality in high transmission settings due to lower specificity and sensitivity. Performance of VA in determining CODs may be better in areas where malaria play only a minor role.

Another limitation of this study is that only one COD with the highest likelihood as displayed by the InterVA output was included into the analysis, possibly leading to a distortion of the estimates among InterVA causes. However, the overall pattern of CODs did not change when comparing the weighted InterVA approach to the one considering only the most likely COD. Unfortunately, no gold standard is available yet against which both methods could be validated. Thus, the true CODs are impossible to obtain [55] and uncertainty levels with either procedure are high [44] in particular for malaria, which is difficult to diagnose accurately without parasitic evidence $[56,57]$. Hence, mortality statistics based on VA have to be interpreted with caution.

This study also provides additional evidence of the seasonal effect on mortality during the rainy season in this part of SSA, which is mostly attributable to malaria [33, $35,58]$. This trend was presented in the regression model with a peak in the wet season, which can be modelled by a parametric sinusoidal curve. The validity of the modelling approach was checked graphically by comparison to the MA of the rates, which were quite similar to the modelled rates. A previous study on seasonal mortality patterns showed that this is an appropriate approach to investigate seasonal mortality patterns [33]. Overall, the mortality rates among the different COD categories showed discrepancies between InterVA and PCVA. The estimated malaria mortality was considerably higher $(20.7 / 1,000)$ among physicians' diagnoses. 


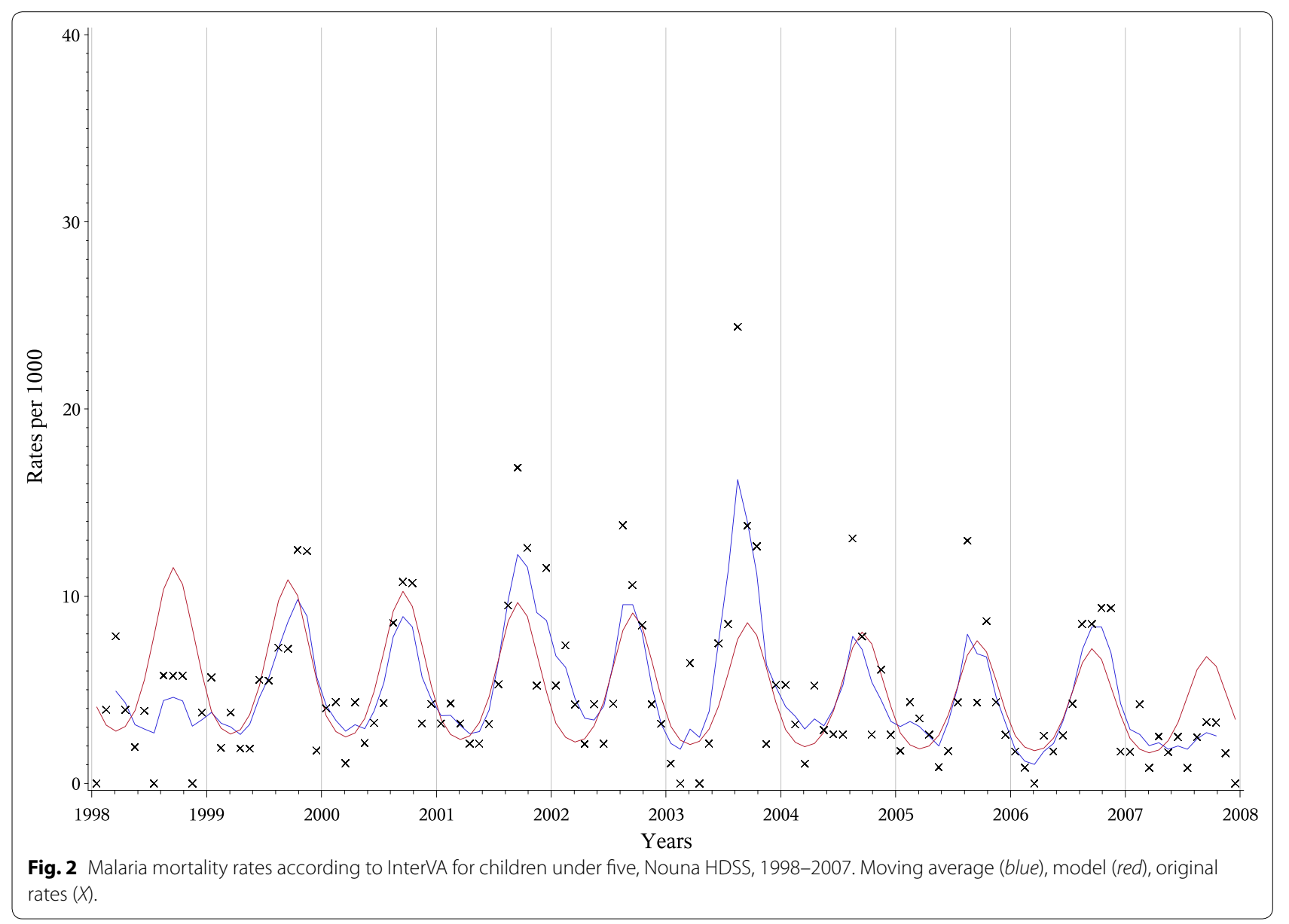

\section{Conclusions}

The present study supports a continuous marked seasonality of malaria mortality in the endemic regions of rural West Africa. Furthermore, it confirms the high impact of malaria on mortality in young children in rural Burkina Faso with excess at around the end of the rainy season.

However, data for the present study was only available up until 2007 and several malaria control interventions have been conducted in the study area afterwards such as the distribution of insecticide-treated nets (ITN) that increased the coverage of at least 1 ITN per household to $99 \%$ in 2011 [59]. Furthermore, artemisinin-based combination therapy (ACT) became available in all Centres de Santé et Promotion Sociale in late 2007 [60]. However, only $27 \%$ of all available ITNs were used and only about half of those were used by either under five children or pregnant women. Also, a large proportion of children were treated with inadequate medications. Thus, it is still important to support and improve malaria programs in SSA.

Moreover, it was shown that the probabilistic InterVA model determines reasonably well seasonal patterns of mortality. Such information will be useful for the planning of health resources and activities in resource-limited settings where reliable estimates of morbidity and mortality are lacking.

\section{Authors' contributions}

EOIK performed the statistical analyses, interpreted the results and drafted and revised the manuscript. OM contributed to the interpretation of the findings. AS supervised the fieldwork and contributed to the interpretation of the data. $\mathrm{HB}$ conceived the study, planned the statistical analysis and contributed in writing the manuscript. All authors read and approved the final manuscript.

\section{Author details}

${ }^{1}$ Institute of Public Health, University of Heidelberg, Heidelberg, Germany. ${ }^{2}$ Centre de Recherche en Santé de Nouna, Nouna, Burkina Faso. ${ }^{3}$ Institute for Medical Biometry, University Medical Center Hamburg-Eppendorf, Hamburg, Germany. ${ }^{4}$ London School of Hygiene and Tropical Medicine, London, UK.

\section{Acknowledgements}

The authors thank Dr. Gisela Kynast-Wolf of the University of Heidelberg for her support and patient help with SAS and the Nouna database during the whole project, Dr. Heribert Ramroth of the University of Heidelberg for his advice and for the constructive discussions on the InterVA approach, the field staff in Nouna/Burkina Faso and Gabriele Stieglbauer for efficient help with data management and programming. This work was supported by the German Research foundation (DFG), Special Research Grant (SFB) 544, Project Z2. We acknowledge the financial support of the Deutsche Forschungsgemeinschaft 
and Ruprecht-Karls-Universität Heidelberg within the funding programme Open Access Publishing.

\section{Compliance with ethical guidelines}

\section{Competing interests}

The authors declare that they have no competing interests.

Received: 6 March 2015 Accepted: 22 July 2015

Published online: 05 August 2015

\section{References}

1. United Nations Inter-Agency Group for Child Mortality Estimation (2011) Levels \& Trends in Child Mortality Report 2011. United Nations, New York, p 1

2. Johnson HL, Liu L, Fischer-Walker C, Black RE (2010) Estimating the distribution of causes of death among children age 1-59 months in highmortality countries with incomplete death certification. Int J Epidemiol 39:1103-1114

3. Hammer GP, Some F, Muller O, Kynast-Wolf G, Kouyate B, Becher H (2006) Pattern of cause-specific childhood mortality in a malaria endemic area of Burkina Faso. Malar J 5:47

4. United Nations (2011) The Millennium Development Goals Report 2011. United Nations, New York, p 42

5. WHO (2014) World Malaria Report 2014. Switzerland World Health Organization, Geneva

6. Byass P (2007) Who needs cause-of-death data? PLoS Med 4:e333

7. Setel PW, Macfarlane SB, Szreter S, Mikkelsen L, Jha P, Stout S et al (2007) A scandal of invisibility: making everyone count by counting everyone. Lancet 370:1569-1577

8. Global location map. http://www.indepth-network.org/index php?option=com_wrapper\&ltemid=287. Accessed 30 Nov 2011

9. Joshi R, Kengne AP, Neal B (2009) Methodological trends in studies based on verbal autopsies before and after published guidelines. Bull World Health Organ 87:678-682

10. Kumar V, Datta N (1986) Lay reporting and verbal autopsy in assessment of infant mortality. Indian J Pediatr 53:672-674

11. Fottrell $E$, Byass $P$ (2010) Verbal autopsy: methods in transition. Epidemiol Rev 32:38-55

12. Anker M (1997) The effect of misclassification error on reported cause-specific mortality fractions from verbal autopsy. Int J Epidemiol 26:1090-1096

13. Quigley MA (2005) Commentary: verbal autopsies—from small-scale studies to mortality surveillance systems. Int J Epidemiol 34:1087-1088

14. Setel PW, Whiting DR, Hemed Y, Chandramohan D, Wolfson LJ, Alberti KG et al (2006) Validity of verbal autopsy procedures for determining cause of death in Tanzania. Trop Med Int Health 11:681-696

15. Snow RW, Armstrong JR, Forster D, Winstanley MT, Marsh VM, Newton CR et al (1992) Childhood deaths in Africa: uses and limitations of verbal autopsies. Lancet 340:351-355

16. Chandramohan D, Maude GH, Rodrigues LC, Hayes RJ (1998) Verbal autopsies for adult deaths: their development and validation in a multicentre study. Trop Med Int Health 3:436-446

17. Adjuik M, Smith T, Clark S, Todd J, Garrib A, Kinfu Y et al (2006) Causespecific mortality rates in sub-Saharan Africa and Bangladesh. Bull World Health Organ 84:181-188

18. Mwanyangala MA, Urassa HM, Rutashobya JC, Mahutanga CC, Lutambi AM, Maliti DV et al (2011) Verbal autopsy completion rate and factors associated with undetermined cause of death in a rural resource-poor setting of Tanzania. Popul Health Metr 9:41

19. Soleman N, Chandramohan D, Shibuya K (2006) Verbal autopsy: current practices and challenges. Bull World Health Organ 84:239-245

20. James SL, Flaxman AD, Murray CJ (2011) Performance of the Tariff Method: validation of a simple additive algorithm for analysis of verbal autopsies. Popul Health Metr 9:31

21. Gajalakshmi V, Peto R (2006) Commentary: verbal autopsy procedure for adult deaths. Int J Epidemiol 35:748-750
22. Kahn K, Tollman SM, Garenne M, Gear JS (2000) Validation and application of verbal autopsies in a rural area of South Africa. Trop Med Int Health 5:824-831

23. Quigley MA, Chandramohan D, Rodrigues LC (1999) Diagnostic accuracy of physician review, expert algorithms and data-derived algorithms in adult verbal autopsies. Int J Epidemiol 28:1081-1087

24. Yang G, Rao C, Ma J, Wang L, Wan X, Dubrovsky G et al (2006) Validation of verbal autopsy procedures for adult deaths in China. Int J Epidemiol 35:741-748

25. Riley I (2011) Computer-based analysis of verbal autopsies: revolution or evolution? Popul Health Metr 9:26

26. Byass P, Huong DL, Minh HV (2003) A probabilistic approach to interpreting verbal autopsies: methodology and preliminary validation in Vietnam. Scand J Public Health Suppl 62:32-37

27. Fottrell E, Kahn K, Ng N, Sartorius B, Huong DL, Van Minh H et al (2010) Mortality measurement in transition: proof of principle for standardised multi-country comparisons. Trop Med Int Health 15:1256-1265

28. Campbell JD, Sow SO, Levine MM, Kotloff KL (2004) The causes of hospital admission and death among children in Bamako, Mali. J Trop Pediatr 50:158-163

29. Tollman SM, Kahn K, Sartorius B, Collinson MA, Clark SJ, Garenne ML (2008) Implications of mortality transition for primary health care in rural South Africa: a population-based surveillance study. Lancet 372:893-901

30. Kynast-Wolf G, Sankoh OA, Gbangou A, Kouyate B, Becher H (2002) Mortality patterns, 1993-98, in a rural area of Burkina Faso, West Africa, based on the Nouna demographic surveillance system. Trop Med Int Health 7:349-356

31. Lawoyin TO (2001) Risk factors for infant mortality in a rural community in Nigeria. J R Soc Promot Health 121:114-118

32. Delaunay V, Etard JF, Préziosi MP, Marra A, Simondon F (2001) Decline of infant and child mortality rates in rural Senegal over a 37-year period (1963-1999). Int J Epidemiol 30:1286-1293

33. Becher $H$, Kynast-Wolf $G$, Sie A, Ndugwa R, Ramroth $H$, Kouyate $B$ et al (2008) Patterns of malaria: cause-specific and all-cause mortality in a malaria-endemic area of west Africa. Am J Trop Med Hyg 78:106-113

34. Sankoh OA, Kynast-Wolf G, Kouyate B, Becher H (2003) Patterns of adult and old-age mortality in rural Burkina Faso. J Public Health Med 25:372-376

35. Kynast-Wolf G, Hammer GP, Muller O, Kouyate B, Becher H (2006) Season of death and birth predict patterns of mortality in Burkina Faso. Int J Epidemiol 35:427-435

36. Kynast-Wolf G, Preuss M, Sie A, Kouyate B, Becher H (2010) Seasonal patterns of cardiovascular disease mortality of adults in Burkina Faso, West Africa. Trop Med Int Health 15:1082-1089

37. Gwer S, Newton CR, Berkley JA (2007) Over-diagnosis and co-morbidity of severe malaria in African children: a guide for clinicians. Am J Trop Med Hyg 77:6-13

38. Chandler Cl, Jones C, Boniface G, Juma K, Reyburn H, Whitty CJ (2008) Guidelines and mindlines: why do clinical staff over-diagnose malaria in Tanzania? A qualitative study. Malar J 7:53

39. Sié A, Louis VR, Gbangou A, Müller O, Niamba L, Stieglbauer G et al (2010) The Health and Demographic Surveillance System (HDSS) in Nouna, Burkina Faso, 1993-2007. Glob Health Action 3. doi:10.3402/gha.v3i0.5284

40. Traoré C (2003) Epidemiology of malaria in a holoendemic area of rural Burkina Faso. PHD thesis. University of Heidelberg

41. Network INDEPTH (2002) Population and Health in Developing Countries. International Development Research Centre, Ottawa

42. InterVA-3 User Guide. http://www.interva.net/2009. Accessed 2 Jan 2012

43. Byass P, Fottrell E, Dao LH, Berhane Y, Corrah T, Kahn K et al (2006) Refining a probabilistic model for interpreting verbal autopsy data. Scand J Public Health 34:26-31

44. Ramroth H, Lorenz E, Rankin JC, Fottrell E, Ye M, Neuhann F et al (2012) Cause of death distribution with InterVA and physician coding in a rural area of Burkina Faso. Trop Med Int Health 17:904-913

45. Black RE, Morris SS, Bryce J (2003) Where and why are 10 million children dying every year? Lancet 361:2226-2234

46. Greenwood BM, Bradley AK, Greenwood AM, Byass P, Jammeh K, Marsh Ket al (1987) Mortality and morbidity from malaria among children in a rural area of The Gambia, West Africa. Trans R Soc Trop Med Hyg 81:478-486 
47. Korenromp EL, Williams BG, Gouws E, Dye C, Snow RW (2003) Measurement of trends in childhood malaria mortality in Africa: an assessment of progress toward targets based on verbal autopsy. Lancet Infect Dis 3:349-358

48. Greenwood BM, Greenwood AM, Bradley AK, Tulloch S, Hayes R, Oldfield FS (1987) Deaths in infancy and early childhood in a well-vaccinated, rural, West African population. Ann Trop Paediatr 7:91-99

49. Muller O, Garenne M, Kouyate B, Becher H (2003) The association between protein-energy malnutrition, malaria morbidity and all-cause mortality in West African children. Trop Med Int Health 8:507-511

50. Snow RW, Craig M, Deichmann U, Marsh K (1999) Estimating mortality, morbidity and disability due to malaria among Africa's non-pregnant population. Bull World Health Organ 77:624-640

51. Greenwood BM, Bojang K, Whitty CJ, Targett GA (2005) Malaria. Lancet 365:1487-1498

52. Lopez AD, Mathers CD, Ezzati M, Jamison DT, Murray CJ (2006) Global and regional burden of disease and risk factors, 2001: systematic analysis of population health data. Lancet 367:1747-1757

53. Whitty CJ, Edmonds S, Mutabingwa TK (2005) Malaria in pregnancy. BJOG 112:1189-1195

54. Todd JE, De Francisco A, O'Dempsey TJ, Greenwood BM (1994) The limitations of verbal autopsy in a malaria-endemic region. Ann Trop Paediatr $14: 31-36$
55. Murray CJ, Lopez AD, Black R, Ahuja R, Ali SM, Baqui A et al (2011) Population Health Metrics Research Consortium gold standard verbal autopsy validation study: design, implementation, and development of analysis datasets. Popul Health Metr 9:27

56. D'Acremont V, Lengeler C, Genton B (2010) Reduction in the proportion of fevers associated with Plasmodium falciparum parasitaemia in Africa: a systematic review. Malar J 9:240

57. Delley V, Bouvier P, Breslow N, Doumbo O, Sagara I, Diakite M et al (2000) What does a single determination of malaria parasite density mean? A longitudinal survey in Mali. Trop Med Int Health 5:404-412

58. Jaffar S, Leach A, Greenwood AM, Jepson A, Muller O, Ota MO et al (1997) Changes in the pattern of infant and childhood mortality in upper river division, The Gambia, from 1989 to 1993. Trop Med Int Health 2:28-37

59. Zollner C, De Allegri M, Louis VR, Ye M, Sie A, Tiendrebeogo J et al (2015) Insecticide-treated mosquito nets in rural Burkina Faso: assessment of coverage and equity in the wake of a universal distribution campaign. Health Policy Plan 30:171-180

60. De Allegri M, Louis VR, Tiendrebeogo J, Souares A, Ye M, Tozan Y et al (2013) Moving towards universal coverage with malaria control interventions: achievements and challenges in rural Burkina Faso. Int J Health Plann Manage 28:102-121

\section{Submit your next manuscript to BioMed Central and take full advantage of:}

- Convenient online submission

- Thorough peer review

- No space constraints or color figure charges

- Immediate publication on acceptance

- Inclusion in PubMed, CAS, Scopus and Google Scholar

- Research which is freely available for redistribution

Submit your manuscript at

www.biomedcentral.com/submit

() Biomed Central 